\title{
Research and development of a numerical model of methane and carbon dioxide filtration in a coal seam
}

\author{
Eugeny Utkaev*, Maxim Makeev, and Artem Gerasimov \\ Federal Research Center for Coal and Coal Chemistry SB RAS, 650000, Kemerovo, Russia,
}

\begin{abstract}
The authors propose to inject $\mathrm{CO}_{2}$ into thin coal seams, which will not be developed and have no industrial value with the concomitant displacement of methane for the purpose of its utilization.
\end{abstract}

\section{Introduction}

According to the Russian Federation Government Resolution signed in 2019 on the adoption of the Paris Climate Agreement, the reduction of $\mathrm{CO}_{2}$ emissions into the atmosphere becomes an urgent issue [1]. The most suitable conditions for $\mathrm{CO}_{2}$ storage thin coal seams are viewed, which will not be developed and are not of industrial value. The process will be lead to methane displacement and its further utilization [2].

For $\mathrm{CO}_{2}$ injection and storage in geological formations, it is possible to use coal seams located on the underlying elevations of the flooded mines, which will act as a "water gate" to prevent $\mathrm{CO}_{2}$ migration to the surface. According to the current industry methodology [3], the influence of the underlying rider coal seams, in terms of methane migration to the overlying seams, is limited to a depth of 30-60 m, depending on mining and geological conditions of bedding. Following these methodological recommendations, it is advisable to select an unproductive coal seam located at a depth of at least $\sim 60 \mathrm{~m}$ below the flooded mine. For mapping of water-resistant layers and aquifers, it is possible to use the method of electrotomography [4].

\section{Analysis}

There are such mines in the Kuznetsk coal basin, and some of them are located near the $\mathrm{CO}_{2}$ source, which may be, for example, coal-fired thermal power plants, The technology for $\mathrm{CO}_{2}$ capture, transportation and storage in Kuzbass conditions is shown in Fig. 1.

The process of carbon dioxide injection into a coal seam has not been sufficiently tested by now and requires the use of modern methods of mathematical modeling. At the same time, much experience has been accumulated in the study of physicochemical processes occurring in a coal seam during $\mathrm{CO}_{2}$ injection $[5,6,7]$, nevertheless, the authors refer to insufficient knowledge of the practical application of this issue.

\footnotetext{
*Corresponding author: m_makeev@uglemetan.ru
} 


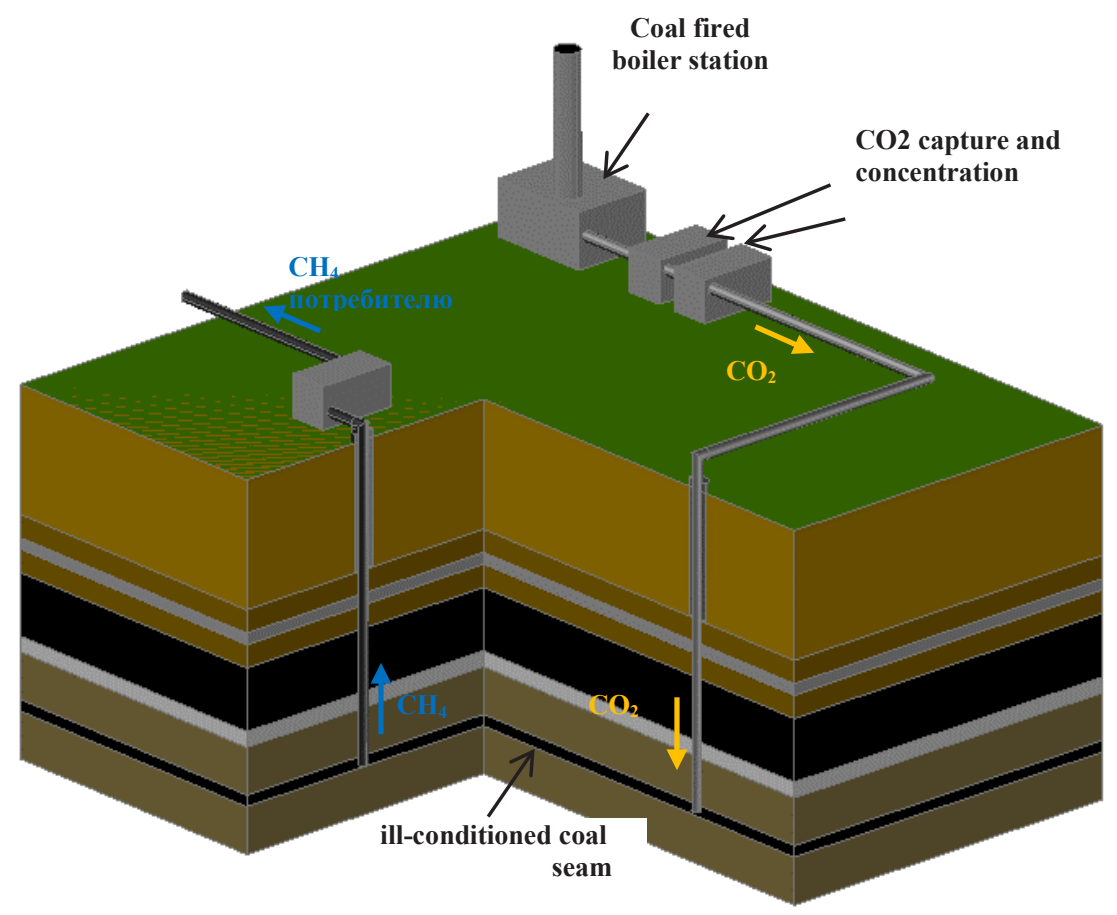

Fig. 1. Technology for $\mathrm{CO}_{2}$ capture, storage and transportation.

When numerically simulating the process of $\mathrm{CO}_{2}$ sequestration into a coal seam in order to displace methane through a borehole for subsequent utilization, it is necessary to determine the $P_{\mathrm{CO} 2}$ pressure to increase the methane recovery, as well as calculate the $P_{\mathrm{CO} 2}$ pressure required to prevent $\mathrm{CO}_{2}$ leakage through the borehole via which methane is displaced.

When constructing a numerical model in the Comsol Multiphysics environment, describing the stationary process of $\mathrm{CO}_{2}$ sequestration into the freshly exposed coal seam surface it was assumed that the process is isothermal, and the area of gas drainage of the considered section of the coal seam with a thickness of һпласт is limited from the above by a low-permeability rock with a thickness of $h_{3}$ (Fig. 2).

Borehole No 1 is used to inject $\mathrm{CO}_{2}$ into the coal seam and is cased to a depth of $H$. Borehole No. 2 is drilled at a distance $L$ from the borehole No 1 and is cased to a depth $H$. In the proposed model, the coal seam pressure $P_{\text {seam }}$ is considered as a function dependent on $\mathrm{CH}_{4}$ pressure in the coal-rock mass, $P^{0}{ }_{C H}$, and $\mathrm{CO}_{2}$ injection pressure into the coal seam $P_{\text {pamp: }}^{0}$

$$
P_{\text {seam }}=\mathrm{f}\left(P^{0}{ }_{C H 4} ; P_{\text {pamp }}^{0}\right)
$$

The design scheme for constructing a numerical model is shown in Fig. 2.

As model parameters data the coal seam permeability and Young's modulus of elasticity were used, also the following characteristics were taken into account: borehole diameter $0.25 \mathrm{~m}$; the depth of the coal seam bedding, $\mathrm{H}-300 \mathrm{~m}$; coal seam thickness on the borehole drilling site, $\mathrm{h},-1 \mathrm{~m}$; coal seam temperature, $\mathrm{t}-30^{\circ} \mathrm{C}$; sorption of coal, $11.2 \mathrm{ml} /$ $\mathrm{g}\left(\mathrm{m}^{3} / \mathrm{t}\right) ; \mathrm{V}_{\text {daf }} 34.2$; AC -5.7 ; Young's modulus of elasticity, E, - $1.5 \cdot 104 \mathrm{MPa}$; coal permeability, $\mathrm{k}-2 \mathrm{mD}$; coal density, $\rho, 1210 \mathrm{~kg} / \mathrm{m}^{3}$ 


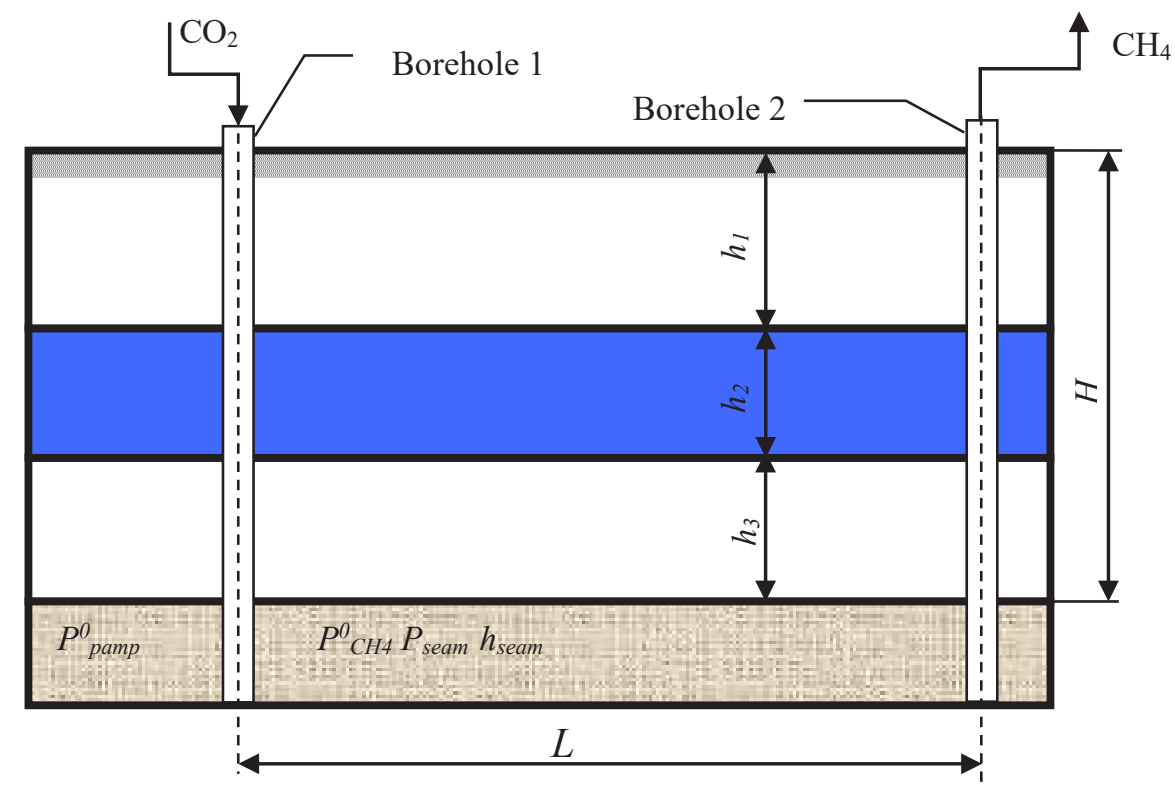

Fig. 2. Design scheme for a numerical model of carbon dioxidthe injection into a coal seam $\left(\mathrm{h}_{1}-\right.$ distance from day surface to aquifer, $\mathrm{m} ; \mathrm{h}_{2}$ - aquifer thickness, corresponding to the extracted thickness of the coal seam, $\mathrm{m}$; $\mathrm{h}_{3}$ - enclosing rock thickness, $\mathrm{m} ; \mathrm{L}$ - boreholes spacing, $\mathrm{m}$ )

To build a numerical model, a hydrodynamics and heat transfer module in the Comsol Multiphysics "Darcy's Law (dl)". environment was chosen. The results of modeling the process of $\mathrm{CO}_{2}$ injection into a coal seam under different pressures (5 atm, $15 \mathrm{~atm}, 30 \mathrm{~atm}$.) employing the "Darcy's Law (dl)". module are shown in Fig. 3.

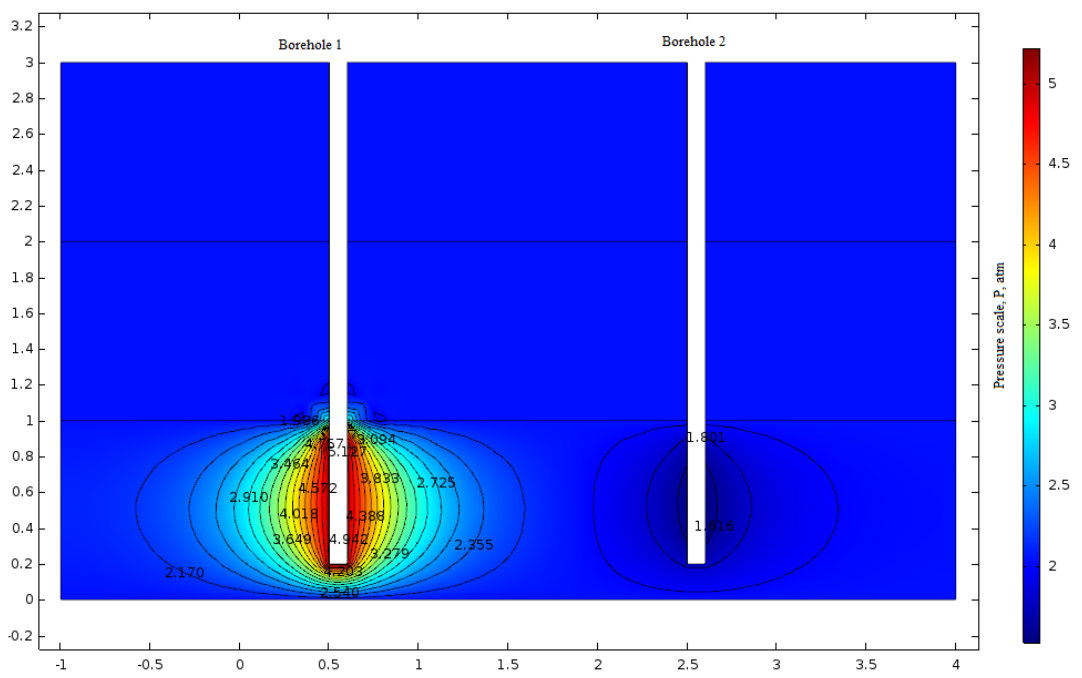

a) 


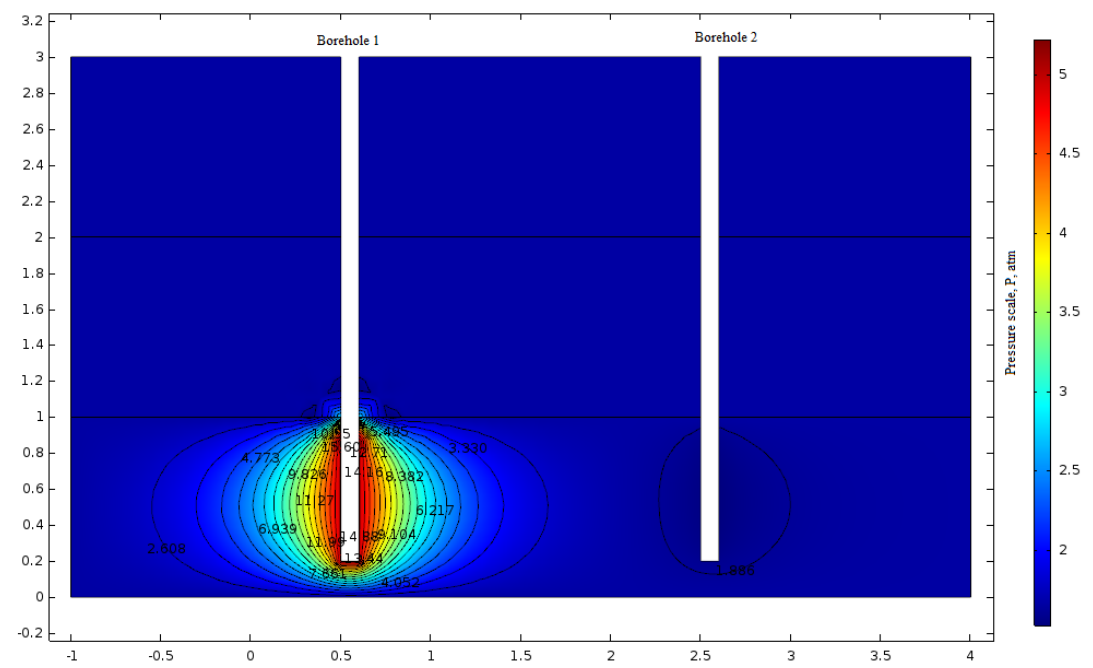

b)

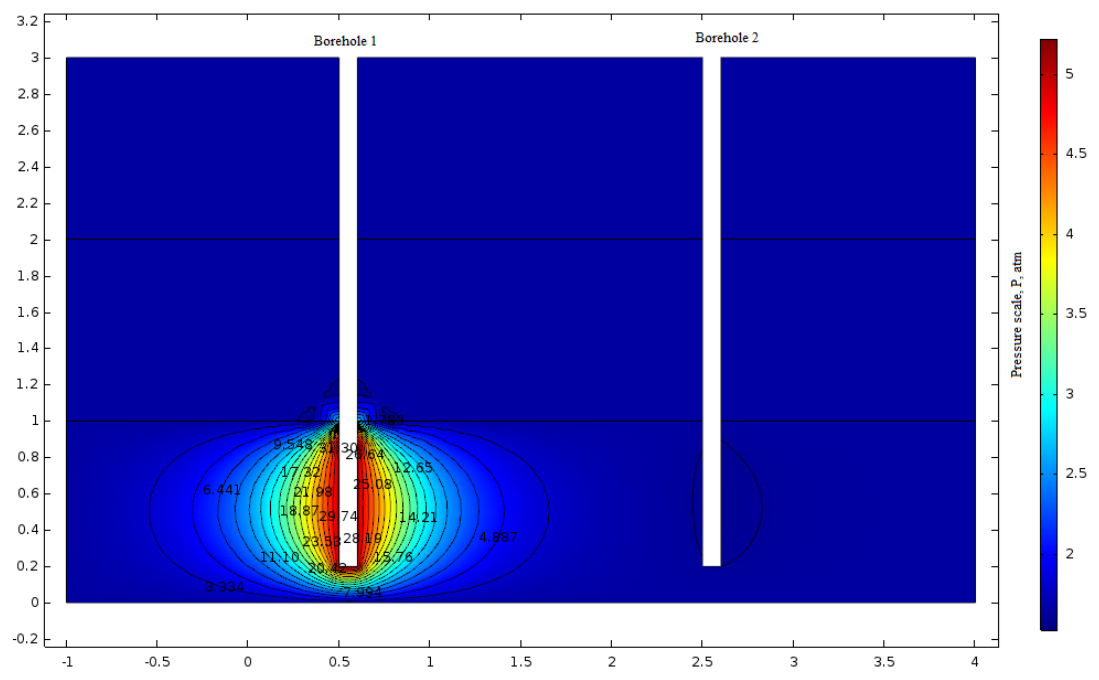

c)

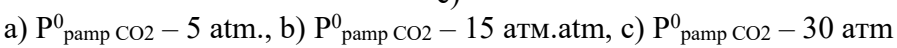

Fig. 3. Model representation of the process of $\mathrm{CO} 2$ injection into a coal seam through the borehole No. 1 at different pressures $P_{\text {pamp } \mathrm{CO} \text {. }}^{0}$

\section{Conclusion}

Based on the assumption that the gas flow of carbon dioxide in accordance with Darcy's Law travels towards a borehole No. 2 (Fig. 2) through the fractured-pore space of the coal seam, this process can be described using the "Subsurface Flow Module" procedure in the Comsol Multiphysics environment.

Problem statement: The coal seam thickness is $2 \mathrm{~m}$. The boreholes spacing is $19 \mathrm{~m}$. From the borehole No. 2, methane comes out from the freshly exposed coal seam surface at a rate of $V_{C H 4}-2^{*} 10^{-4} \mathrm{M} / \mathrm{c}, \mathrm{m} / \mathrm{s}$, and the connection between the boreholes is carried out via a fractured pore space, represented in the model in the form of a "rectangle" with a size of $0.12 \times 18 \mathrm{~m}$. When $\mathrm{CO}_{2}$ is supplied into the borehole No. 1 at $30 \mathrm{~atm}$ pressure. in 20 
minutes the pressure will decrease in the area of borehole No. 2, which will lead to the formation of the united system of fractures between the boreholes. The simulation results are shown in Fig. 4.

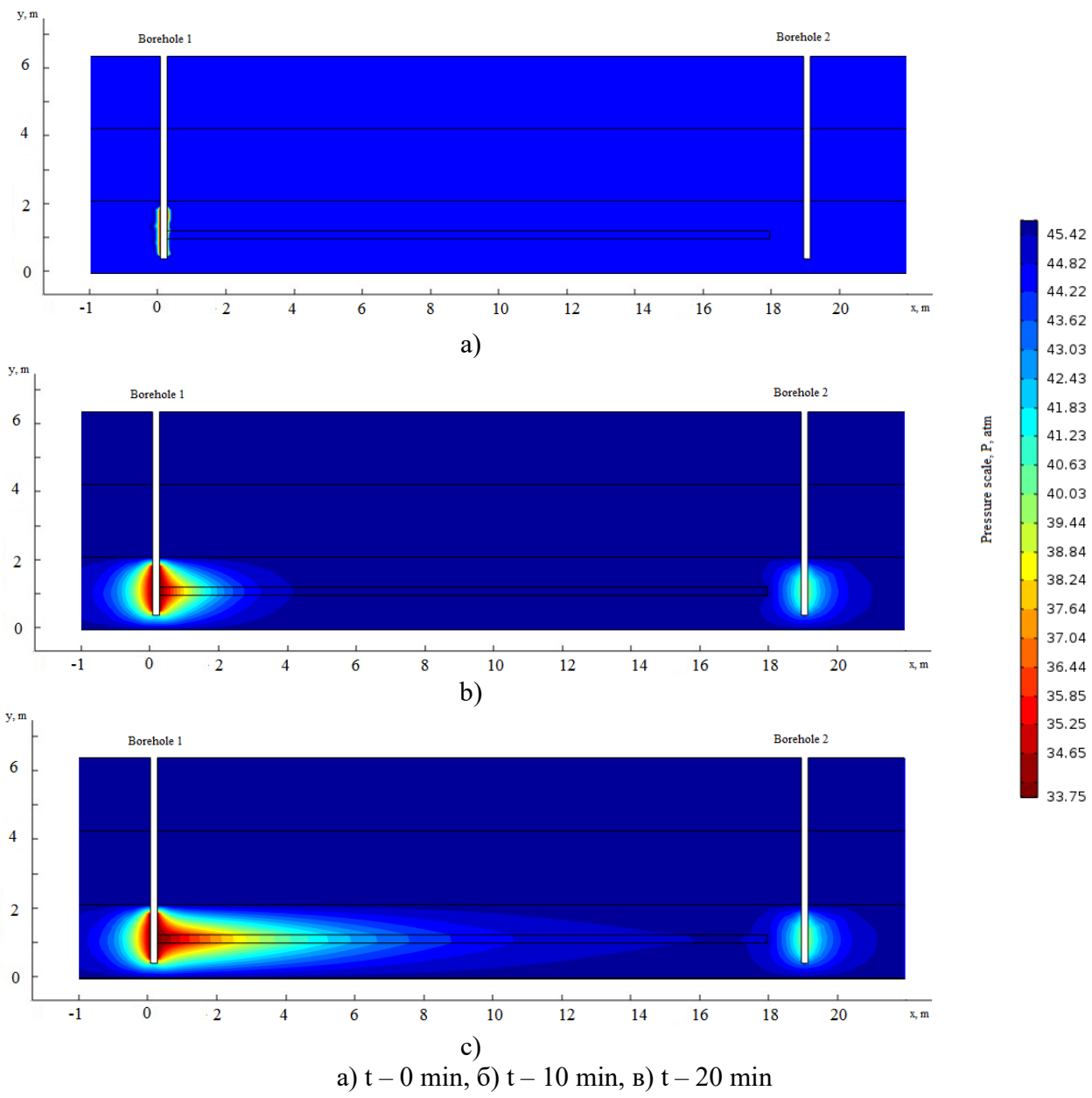

Fig. 4. Model representation of the process of $\mathrm{CO} 2$ injection into a coal seam through a borehole No. 1 with a directed fracture at $P^{0}$ pamp CO2-30 atm. depending on time $t$.

Numerical models of the stationary process of carbon dioxide sequestration into a coal seam are considered. As a result of modeling, it was found that at a distance of 19 meters between the boreholes involved into the carbon dioxide sequestration, after 20 minutes, a decrease in pressure in the area of the methane recovery borehole is registered. To assess the borehole condition, it is possible to use the echolocation method or hydrodynamic research methods [8-10].

\section{References}

1. Resolution of the Russian Federation Government as of September 21, 2019 No. 1228 "On the adoption of the Paris Agreement" 
2. O.V. Tailakov, D.N. Zastrelov, et al., Gas industry, 12, 86-87 (2013)

3. Order of Rostekhnadzor dated 01.12.2011 N 679 (as amended on 20.05.2015) "On approval of the Instructions for coal mines degasification" (Registered in the Ministry of Justice of Russia on 29.12.2011 N 22811)

4. O.V. Tailakov, D.N. Zastrelov, et al., Bulletin of the Scientific Center for the Safety of Work in the Coal Industry, 1, 30 (2016)

5. I.A. Ettinger, Gas intensity of fossil coals (Nedra, Moscow, 1966)

6. D.N. Zastrelov, M.P. Makeev, et al., Science-intensive technologies for the development and use of mineral resources, 5, (2019)

7. O.V. Tailakov, E.A. Utkaev, GIAB, 7, 145-149 (2008)

8. O.V. Tailakov, E.A. Utkaev, M.P. Makeev, Actual problems of modern mechanical engineering: proceedings of the International Scientific and Practical Conference, 176179 (2014)

9. O.V. Tailakov, E.A. Utkaev, et al., Applied Mechanics and Materials, 349-353 (2015)

10. O. Tailakov, D. Zastrelov, et al., E3S Web of Conferences, 15 (2017) 